\title{
BMJ Open Social and spatial inequalities in allostatic load among adults in China: a multilevel longitudinal study
}

Fan Mao (i) , ${ }^{1}$ Thomas Astell-Burt, ${ }^{2}$ Xiaoqi Feng, ${ }^{2}$ Yunning Liu, ${ }^{1}$ Jianqun Dong, ${ }^{1}$ Shiwei Liu, ${ }^{1}$ Lijun Wang, ${ }^{1}$ Yingying Jiang, ${ }^{1}$ Wenlan Dong, ${ }^{1}$ Maigeng Zhou, ${ }^{1}$ Limin Wang ${ }^{1}$

To cite: Mao F, AstellBurt T, Feng $X$, et al. Social and spatial inequalities in allostatic load among adults in China: a multilevel longitudinal study. BMJ Open 2019;9:e031366. doi:10.1136/ bmjopen-2019-031366

- Prepublication history and additional material for this paper are available online. To view these files, please visit the journal online (http://dx.doi. org/10.1136/bmjopen-2019031366).

MZ and LW contributed equally.

FM and TA-B are joint first authors.

Received 13 May 2019 Revised 27 August 2019 Accepted 01 October 2019

Check for updates

(c) Author(s) (or their employer(s)) 2019. Re-use permitted under CC BY-NC. No commercial re-use. See rights and permissions. Published by BMJ.

For numbered affiliations see end of article.

Correspondence to Professor Maigeng Zhou; maigengzhou@126.com

Professor Limin Wang; wlm65@126.com

\section{ABSTRACT}

Objectives To investigate potential geographical and socioeconomic patterning of allostatic load (AL) in China. Design Multilevel longitudinal study of the 2010 Chronic Disease Risk Factor Surveillance linked to the National Death Surveillance up to 31 December 2015.

Setting All 31 provinces in China, not including Hong Kong, Macao or Taiwan.

Participants $96466 \geq 18$ years old (women=54.3\%). Exposures Person-level educational attainment and mean years of education in counties.

Outcome AL was measured using clinical guidelines for nine biomarkers: body mass index; waist circumference; systolic blood pressure; diastolic blood pressure; fasting blood glucose; total cholesterol; triglycerides; highdensity lipoprotein cholesterol; low-density lipoprotein cholesterol.

Results Multilevel logistic regressions adjusted for sex, age, marital status, person-level education, county mean years of education and urban/rural reported ORs of 1.22 (95\% Cl 1.08 to 1.38) for 5-year all-cause mortality $(\mathrm{n}=3284)$ and 1.20 (1.04-1.37) for deaths from noncommunicable diseases $(n=2891)$ among people in AL quintile 5 (high) compared with quintile 1 (low). The median rate ratio estimated from unadjusted multilevel negative binomial regression showed AL clustered geographically (province $=1.14$; county $=1.12$; town $=1.11$; village=1.14). After adjusting for aforementioned confounders, AL remained higher with age (rate ratio 1.02, $95 \% \mathrm{Cl} 1.02$ to 1.02), higher in women compared with men $(1.17,1.15$ to 1.19$)$, lower among singletons $(0.83$, 0.81 to 0.85$)$ and widowers $(0.96,0.94$ to 0.98$)$. AL was lower among people with university-level compared with no education $(0.92,0.89$ to 0.96$)$, but higher in counties with higher mean education years $(1.03,1.01$ to 1.05$)$. A two-way interaction suggested AL was higher (1.04, 1.02 to 1.06) among those with university-level compared with no education within counties with higher mean years of education. Similar results were observed for alternative constructions of AL using 75th and 80th percentile cutpoints.

Conclusions AL in China is patterned geographically. The degree of association between $A L$ and person-level education seems to be dependent on area-level education, which may be a proxy for other contextual factors that warrant investigation.
Strengths and limitations of this study

Multilevel longitudinal analysis of a large, representative national sample.

- Nine biomarkers were used to construct three indicators of allostatic load.

- Linkage to routinely collected, representative, national death surveillance.

- Study lacked repeated measurements of biomarkers to examine change.

- Study was limited to 5 years and some biomarkers were not available.

\section{INTRODUCTION}

Evolving epidemiological understandings of how environmental exposures 'get under the skin' for some people more than others, and especially among marginalised and socioeconomically disadvantaged groups, are increasingly recognising the concept of 'allostatic load' (AL). ${ }^{12}$ AL refers to the neurophysiological costs humans can accumulate over time as a result of dysregulations in multiple physiological systems in response to repeated exposures of psychological, physical and environmental stress. ${ }^{34}$ An example of a stressor is unfavourable employment conditions. ${ }^{5}$ Many studies have hypothesised or demonstrated links between $\mathrm{AL}$ and a range of health outcomes including depression and Alzheimer's disease, ${ }^{6}$ cardiovascular diseases, ${ }^{7}$ chronic fatigue syndrome ${ }^{8}$ sleep problems, ${ }^{9}$ depressive symptoms ${ }^{10}$ and all-cause mortality. ${ }^{11}$ Some epidemiological studies have linked allostatic load with arealevel deprivation ${ }^{12}$ and related factors such as green space ${ }^{13}$ and perceptions of neighbourhood quality. ${ }^{14}$

Some studies have already documented association between allostatic load and person-level indicators of socioeconomic circumstances. ${ }^{15}$ Scant attention, until very recently, ${ }^{16}$ has been paid to investigating 
potential interactions between person and area-level indicators of socioeconomic circumstances on AL. On one hand, it might be hypothesised that the impact of low personal socioeconomic circumstances on the development of AL might be compounded by living in a socioeconomically disadvantaged area (the 'deprivation amplification' hypothesis). ${ }^{17}$ In such a scenario, were that person able to move to a more affluent area, perhaps the impact of their personal socioeconomic disadvantage might be lessened (the 'pull up/pull down' hypothesis). ${ }^{18}$ The aforementioned recent study ${ }^{16}$ found evidence for these hypotheses in a multicohort study wherein AL was higher among residents of socioeconomically disadvantaged areas and, especially, for those with low person-level socioeconomic circumstances.

On the other hand, the experience of a person with low personal socioeconomic circumstances living within a context of affluence may have a negative impact on their AL (the 'relative deprivation' hypothesis). ${ }^{19}$ As people make cognitive comparisons, those with low person-level socioeconomic circumstances may make negative selfappraisals of their disadvantage to a referent group. These relative disadvantages can be internalised as unjust and arouses emotions of anger, envy and resentment, ${ }^{20}$ the result being exposure to chronic psychosocial stress that can wear a person down over time. ${ }^{21}$ Our earlier study ${ }^{22}$ provided some indirect evidence for this hypothesis in China in which a contingency of association between body mass index (BMI; a biomarker commonly used in the construction of AL indicators) and personal educational attainment was observed across strata of the mean years of education within counties. In counties with fewer mean years of education, higher personal education was associated with higher BMI on average. By contrast, in counties with higher mean years of education, higher personal education was associated with lower BMI on average.

Building on this previous work, our aim was to test these competing hypotheses with respect to AL. To achieve this aim, we addressed the following objectives:

1. We constructed a measure of AL;

2. We validated the AL indicator as a predictor of allcause and cause-specific mortality;

3. We examined the socioeconomic patterning of AL with respect to person and area-level educational attainment; and

4. We tested the sensitivity of our findings with respect to two alternative constructions of AL.

\section{MATERIALS AND METHODS}

\section{Patient and public involvement}

This study is an analysis of two linked sources of secondary health data. Patients were not involved in the design or conduct of this study.

\section{Participants}

The China Chronic Disease and Risk Factors Surveillance (CCDRFS) is a nationwide cross-sectional study repeated every 3 years. It is designed to measure the epidemiology of chronic disease and associated risk factors in a nationally representative sample of the general population. It is presided over by the National Center for Chronic and Non-communicable Disease Control and Prevention, Chinese Center for Disease Control and Prevention (China CDC).

This study makes use of the 2010 CCDRFS, which was approved by the China CDC ethics committee. The 2010 CCDRFS was conducted between August and December 2010 using the National Disease Surveillance Point (DSP) system. The DSP system includes a random selection of 161 urban districts and rural counties (DSPs) across the 31 provinces, municipalities and autonomous regions in mainland China.

Participants were selected by a multistage probability sampling design. Four subdistricts were selected with probability proportional to size within each DSP, followed by three neighbourhood communities or administrative villages selected proportional to size within each subdistrict. A total of 50 households were randomly selected within each community or village from lists of all households available. A single adult (aged $\geq 18$ years) was selected at random from each household using a Kish selection table. The final sample was 98058 respondents from 1933 villages, 644 towns of 161 counties in all 31 provinces.

A questionnaire and face-to-face interview was administered to every respondent by trained staff to collect demographic, social and health data. Objective measures of height, weight, waist circumference and blood pressure were all performed by trained staff within examination centres at health stations or community clinics nearby participants' homes. Laboratory tests were conducted for the following biomarkers: fasting blood glucose and blood lipids (total cholesterol, triglycerides, and high-density and low-density lipoprotein cholesterol). ${ }^{23}$

\section{Allostatic load}

Three AL indicators were constructed from nine biomarkers of the cardiometabolic system. These biomarkers were BMI, waist circumference, systolic blood pressure, diastolic blood pressure, fasting blood glucose, total cholesterol, triglycerides, high-density lipoprotein cholesterol and low-density lipoprotein cholesterol. All of these biomarkers were continuous variables. The primary AL indicator was constructed by summing biomarker data that were dichotomised with clinical guidelines applied to derive relevant cut-points ( $1=$ high risk; $0=$ nothigh risk). Two secondary AL indicators were calculated using the 75th percentile and 80th percentile as cut-points to re-dichotomise each of the biomarkers for purposes of checking the consistency of results across different definitions. Table 1 reports the cut-points for each biomarker used in the three AL indicators. 
Table 1 Biomarkers used to summarise allostatic load and corresponding cut-point

\begin{tabular}{llll}
\hline Biomarkers used & $\begin{array}{l}\text { Clinical } \\
\text { guideline* }\end{array}$ & $\begin{array}{l}\text { Quartile } \\
\text { analysis }\end{array}$ & $\begin{array}{l}\text { Quintile } \\
\text { analysis }\end{array}$ \\
\hline BMI & $\geq 28$ & $\geq 26.2$ & $\geq 26.8$ \\
$\begin{array}{l}\text { Waist circumstance } \\
\text { (cm) }\end{array}$ & $\begin{array}{l}\geq 85 \text { (Male) } \\
\text { (Female) }\end{array}$ & $\geq 90$ (Male) & $\geq 92$ (Male) \\
& $\geq 140$ & $\geq 144$ & $\geq 149$ \\
$\begin{array}{l}\text { Systolic blood } \\
\text { pressure (mm Hg) }\end{array}$ & & & \\
$\begin{array}{l}\text { Diastolic blood } \\
\text { pressure (mm Hg) }\end{array}$ & $\geq 90$ & $\geq 88$ & $\geq 90.5$ \\
Fasting blood & $\geq 7.0$ & $\geq 5.88$ & $\geq 6.03$ \\
glucose (mmol/L) & & & \\
TC (mmol/L) & $\geq 5.18$ & $\geq 4.75$ & $\geq 4.94$ \\
TG (mmol/L) & $\geq 1.70$ & $\geq 1.59$ & $\geq 1.77$ \\
LDL-C (mmol/L) & $\geq 3.37$ & $\geq 2.77$ & $\geq 2.92$ \\
HDL-C (mmol/L) & $<1.04$ & $\leq 0.89$ & $\leq 0.84$ \\
& & $($ Lowest)† & (Lowest)† \\
\hline
\end{tabular}

*High risk of al the nine biomarkers were defined according to the latest clinical guideline for Chinese.

†High risk of HDL-C was defined as a value equal to or less than the 25th or 20th percentile.

BMI, body mass index; HDL-C, high-density lipoprotein cholesterol; LDL-C, low-density lipoprotein cholesterol; TC, total cholesterol; TG, triglycerides.

\section{Socioeconomic variables}

Education was selected as the socioeconomic variable on which to focus as it is less vulnerable to reporting bias and less prone to reverse causation than alternatives like income. ${ }^{2425}$ Education was measured for each individual respondent using questionnaire data to inform the highest attainment up to that point (none/less than primary school, primary school, secondary school, university). The mean number of years of education was also measured for counties using census data (mean $=9$, low $=5$, high=13). The combination of these variables afforded opportunities to examine AL among people across different combinations of personal educational attainment and the level of education among the people with whom they live nearby. The county was suitable for the areal unit of analysis as it is sufficiently large and heterogeneous to allow for 'off-diagonal' cases to be identified, wherein people with lower educational attainment may be resident in areas with higher mean years of education and vice versa.

\section{Mortality}

Each indicator of AL was tested with respect to all-cause and cause-specific mortality. Mortality variables were identified based on previous studies for purposes of validating associations: all-cause mortality; mortality from non-communicable diseases (NCDs). AL was also tested with respect to a range of mortality causes that are not plausibly related for purposes of falsification: infectious diseases; injuries.

The aforementioned causes of death, where applicable, were identified using ICD-10 codes in the national mortality surveillance 2011 to 2015 linked to the 2010 CCDRFS. Linkage was conducted where possible with the National ID, unique 18 numbers for each individual in China. The ID number was initially used to scan for a mortality record. For all the remaining participants, which included those without a National ID or those not matched in the first step, some basic demographic characteristics such as name, sex, age and address information were jointly used to identify mortality records. In order to guarantee the quality of the data linkage, two researchers conducted both of the aforementioned steps independently. The consistency of the results from each independent researcher were then checked. A total of 3365 from the 98058 participants were found to have died between 2011 and 2015. The annual mortality of these participants were close to the corresponding national mortality.

\section{Confounding}

Variables previously found to be correlated with AL and indicators of socioeconomic circumstances were taken into account. These include the age, sex and marital status of each respondent, as well as whether they lived in an urban or rural county.

\section{Data analysis}

Cross-tabulations, means and medians were used to describe sample characteristics and distributions of each AL variable. Multilevel logistic regressions adjusted for confounding were used to confirm higher odds of allcause and NCD-related mortality with each AL variable. These models took into account clustering of respondents within villages, towns, counties and provinces. Further models were then fitted for mortality from injuries and infectious diseases as negative control outcomes for purposes of falsification since these causes of death are less plausibly related to AL.

Multilevel negative binomial regressions were then used to examine geographical clustering and correlates of each AL outcome variable. Although the AL variables were counts, tests showed signs of overdispersion rendering a Poisson regression less appropriate. These models also took into account clustering of respondents within villages, towns, counties and provinces. Null models (model 1 ) were fitted initially to examine variance components and calculate median rate ratios. ${ }^{26}$ Covariates were then added in the following sequence: (model 2) sex, age, marital status and urban/rural; (model 3) model 2+person-level education; (model 4) model $2+$ county-level mean years of education; (model 5) model $2+$ person-level education and county-level mean years of education. A sixth model was then estimated based on model 5, with the addition of a two-way interaction term between the person-level education and county-level 
mean years of education variables. All the data clean and primary analysis were conducted in SAS software (V.9.3). All modelling was conducted in MLwiN V.2.30 software. Statistical significance was set at two-tailed $p$ values less than 0.05 .

\section{RESULTS}

A total of 1592 respondents were excluded due to one or more missing biomarker values for purposes of consistency in measuring AL. Excluded respondents were similar to the 96466 retained in the sample in terms of sex $(p=0.4519)$ and age $(p=0.0939)$. The remaining respondents in the sample were resident in 1927 villages and 644 towns across 161 counties and in all 31 provinces of China.

Correlation coefficients were calculated to test how closely each of the AL variables aligned with each other. Between AL1 (clinical cut-points) and AL2 (75th percentile cut-points), the correlation coefficient was 0.85 $(\mathrm{p}<0.001)$. The correlation coefficients between AL1 and AL3 (80th percentile cut-points) and AL2 and AL3 were $0.86(\mathrm{p}<0.001)$ and $0.94(\mathrm{p}<0.001)$, respectively.
Approximately $54.3 \%$ of these participants were women, $77.7 \%$ were under 60 years old, $81.3 \%$ were married, $60.3 \%$ were from rural counties and $8.3 \%$ had education attainment at university (table 2). AL tended to be higher among men compared with women, higher with age, lower with higher educational attainment, higher among people who were widowed compared with those who were married and higher among those resident in urban compared with rural counties.

A total of 3284 of the 96466 respondents died by 31 December 2015. The number of deaths by category was 2891 from NCDs, 264 from injuries and 103 from infectious diseases. Women and younger respondents had lower odds of all-cause and cause-specific mortality (table 3). Respondents who were widowed had higher odds of all mortality outcomes compared with those who were married. The odds of all-cause and NCD-related mortality were higher among respondents in rural compared with urban counties. A university-level education was associated with lower odds of all mortality outcomes. Higher mean years of education within the county of residence were associated with lower odds of injury-related mortality only. Respondents in the fifth quintile (high) compared

Table 2 Sample characteristics and mean and median allostatic load variables

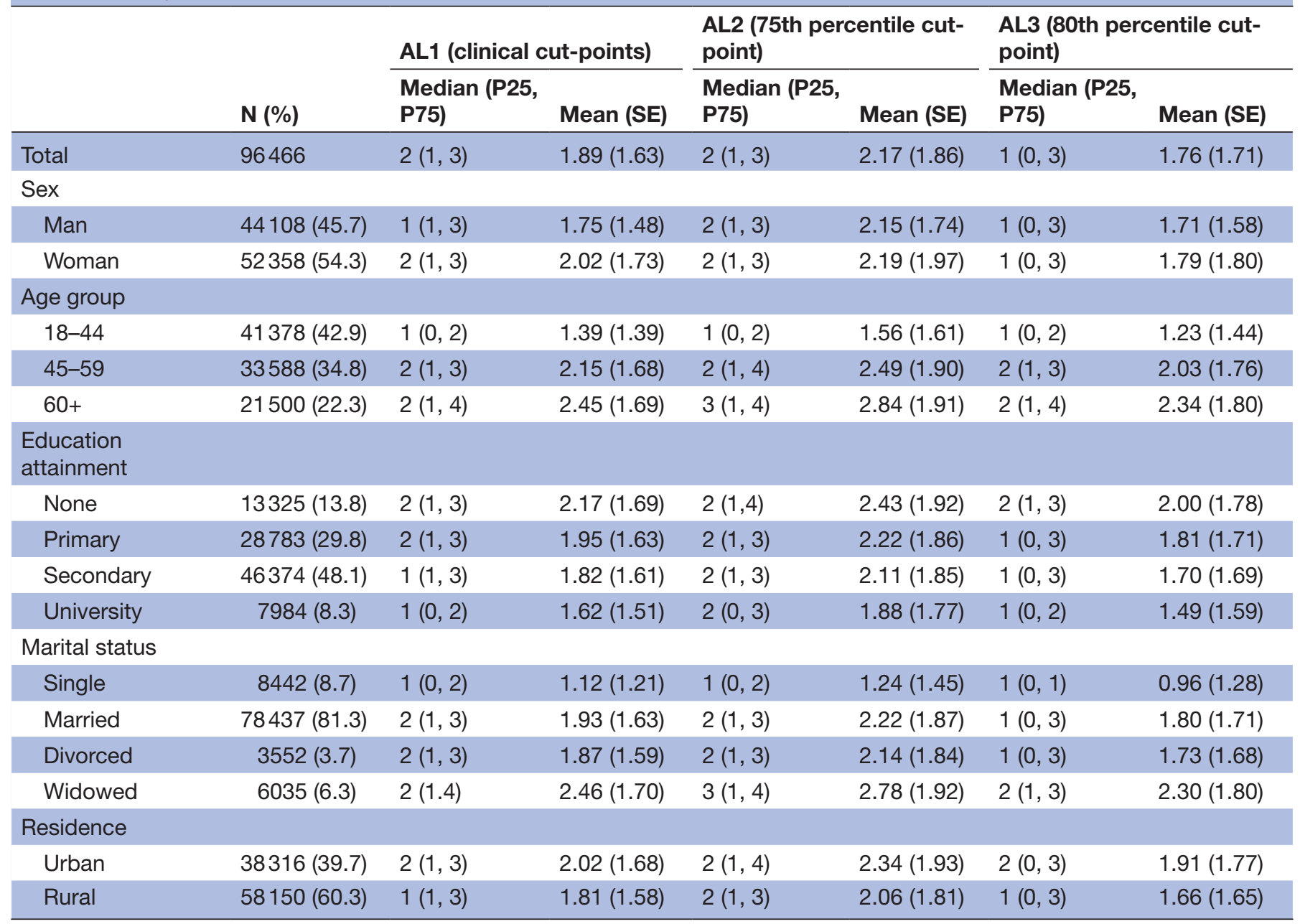


Table 3 Association between all-cause and cause-specific mortality with allostatic load (defined using clinical cut-points of nine biomarkers)

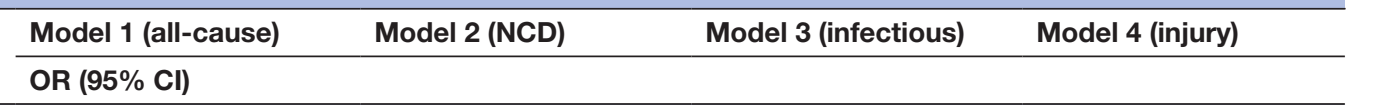

\begin{tabular}{|c|c|c|c|c|}
\hline \multicolumn{5}{|l|}{ Fixed effect } \\
\hline Constant & 0.023 (0.018 to 0.030$)$ & 0.019 (0.015 to 0.024$)$ & 0.001 (0.000 to 0.002$)$ & $0.004(0.002$ to 0.006$)$ \\
\hline \multicolumn{5}{|l|}{ Sex (ref: man) } \\
\hline Age & $1.061(1.057 \text { to } 1.065)^{*}$ & $1.071(1.065 \text { to } 1.078)^{\star}$ & $1.039(1.019 \text { to } 1.059)^{*}$ & $1.010(0.998$ to 1.022$)$ \\
\hline $\mathrm{Age}^{2}$ & $1.000(1.000$ to 1.000$)$ & $1.000(1.000$ to 1.000$)$ & $1.001(1.001 \text { to } 1.001)^{*}$ & $1.000(1.000$ to 1.000$)$ \\
\hline Divorced & $1.151(0.935$ to 1.417$)$ & $1.042(0.827$ to 1.313$)$ & 1.519 (0.579 to 3.984$)$ & $1.944(1.177 \text { to } 3.212)^{*}$ \\
\hline Widowed & $1.192(1.071 \text { to } 1.328)^{\star}$ & $1.183(1.058 \text { to } 1.323)^{\star}$ & $0.920(0.505$ to 1.677$)$ & 1.305 (0.820 to 2.076$)$ \\
\hline \multicolumn{5}{|l|}{ Residence (ref: urban) } \\
\hline Rural & $1.492(1.222 \text { to } 1.822)^{\star}$ & $1.523(1.238 \text { to } 1.875)^{\star}$ & 0.923 (0.418 to 2.038$)$ & $1.095(0.753$ to 1.593$)$ \\
\hline University & $0.448(0.347 \text { to } 0.578)^{\star}$ & $0.455(0.346 \text { to } 0.599)^{*}$ & $0.500(0.115$ to 2.171$)$ & $0.384(0.164 \text { to } 0.904)^{\star}$ \\
\hline Area-level mean years of education & 1.018 (0.949 to 1.093$)$ & $1.037(0.964$ to 1.115$)$ & $0.849(0.634$ to 1.137$)$ & $0.809(0.708 \text { to } 0.924)^{\star}$ \\
\hline \multicolumn{5}{|l|}{ Allostatic load (ref: 1st quintile-0) } \\
\hline 2nd quintile-1 & $1.088(0.965$ to 1.226$)$ & $1.096(0.963$ to 1.248$)$ & $1.097(0.614$ to 1.960$)$ & $0.989(0.688$ to 1.421$)$ \\
\hline 3rd quintile-2 & $1.084(0.960$ to 1.224$)$ & $1.080(0.947$ to 1.232$)$ & $0.731(0.380$ to 1.406$)$ & $1.130(0.772$ to 1.652$)$ \\
\hline 4th quintile-3 & 1.126 (0.988 to 1.284$)$ & 1.122 (0.976 to 1.289$)$ & $0.875(0.440$ to 1.740$)$ & $1.130(0.738$ to 1.729$)$ \\
\hline 5th quintile-4-9 & $1.219(1.075 \text { to } 1.382)^{\star}$ & $1.195(1.044 \text { to } 1.368)^{*}$ & $0.998(0.520$ to 1.917$)$ & $1.236(0.819$ to 1.866$)$ \\
\hline \multicolumn{5}{|l|}{ Random effects } \\
\hline $\begin{array}{l}\text { Variance between provinces (SE) } \\
(n=31)\end{array}$ & $0.094(0.034)^{*}$ & $0.076(0.030)^{\star}$ & $1.248(0.472)^{\star}$ & $0.000(0.000)$ \\
\hline MOR (median OR) & 1.338 & 1.356 & 1.422 & 1.445 \\
\hline $\begin{array}{l}\text { Variance between villages (SE) } \\
(n=1927)\end{array}$ & $0.057(0.026)^{*}$ & $0.031(0.028)$ & $4.166(0.867)^{\star}$ & $0.000(0.000)$ \\
\hline MOR (median OR) & 1.256 & 1.183 & 7.007 & 1.000 \\
\hline
\end{tabular}

${ }^{*} \mathrm{P}<0.05$.

with the first quintile (low) of AL had 1.22 (1.08 to 1.38) and 1.20 (1.04 to 1.37) odds of all-cause and NCD-related mortality, respectively. There was no convincing evidence of association between AL and mortality from injuries or infectious diseases. Similar findings were observed for these mortality outcomes and the AL indicators derived using 75th and 80th percentiles (online supplementary tables 1-4).

The variance components model (table 4, model 1) reported geographical variation in AL between provinces (median rate ratio: 1.144$)$, counties (1.119), towns (1.105) and villages (1.141). AL was higher among women (rate ratio $1.132,95 \%$ CI 1.121 to 1.143 ) and with age (1.015, 1.015 to 1.015 ) (model 2). AL was lower among singletons $(0.827,0.808$ to 0.847$)$ and widowers $(0.956,0.937$ to 0.975$)$ compared with respondents who were married. Respondents living in rural areas tended to have lower AL than their urban-based counterparts $(0.924,0.887$ to 0.963).

Adding person-level education (model 3) led to a minor attenuation of the difference between men and women and had negligible impact on the other 


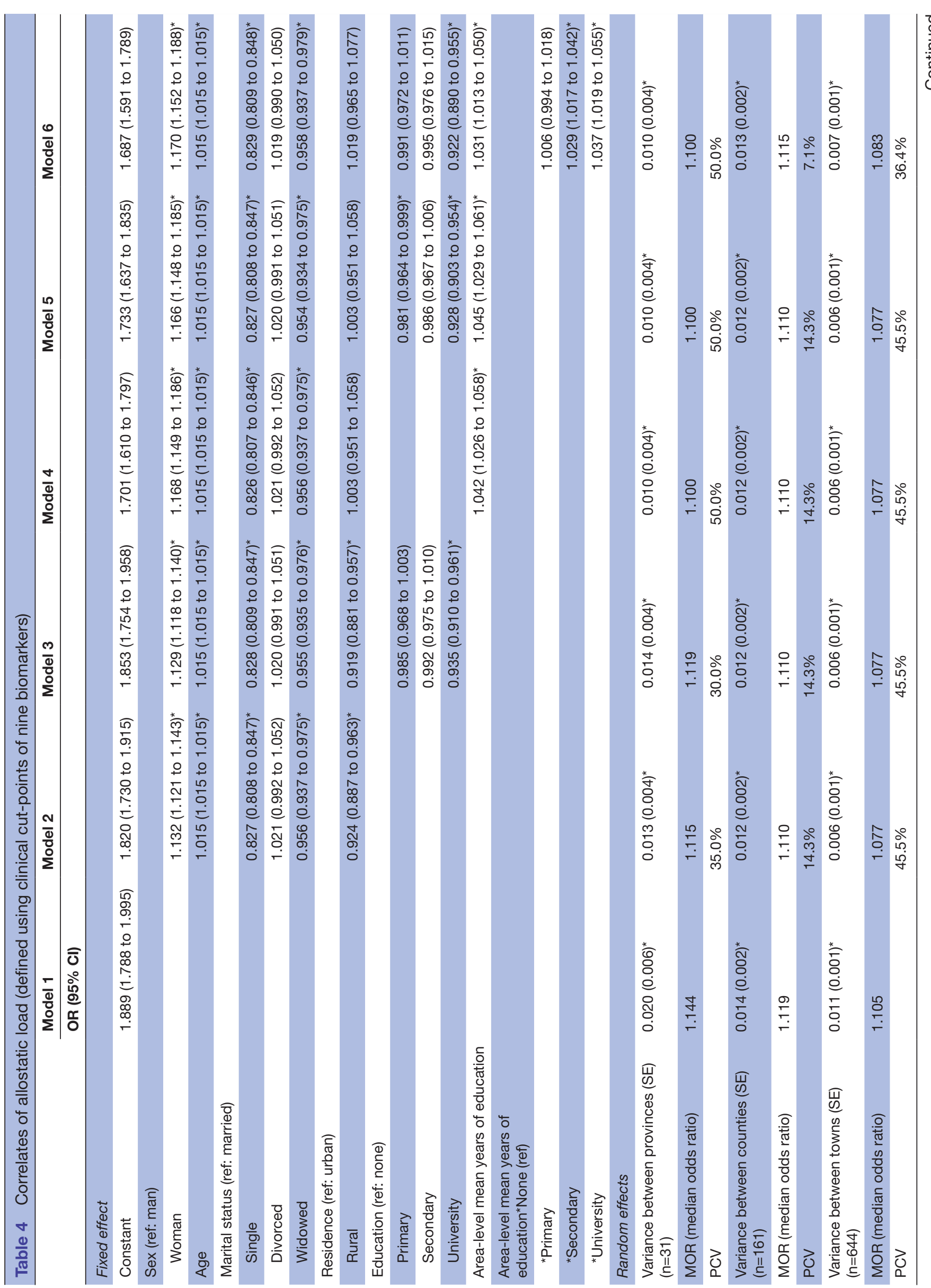

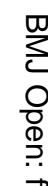

$\stackrel{\vec{F}}{\stackrel{\vec{F}}{+}}$

흠

$\stackrel{\frac{\pi}{\Phi}}{\varrho}$

क

$\overrightarrow{0}$

$\overrightarrow{\vec{\omega}}$

욱

$\Phi$

กิ่

它

बั

옥

N

zo

衰 


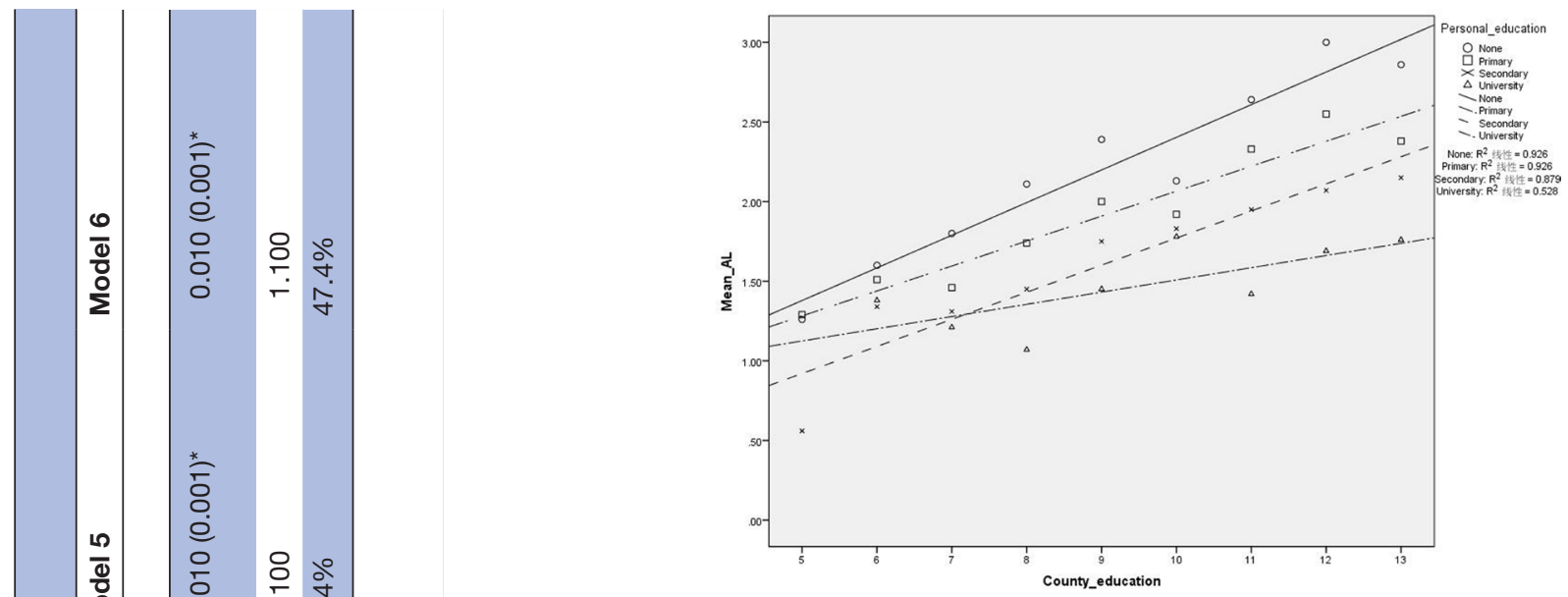

Figure 1 Mean allostatic load (AL) with respect to personal education and county education.

parameters. Respondents with university-level education had lower AL compared with their peers without educational qualifications $(0.935,0.910$ to 0.961$)$. Substituting the county-level mean years of education for the personlevel educational attainment variable also attenuated the difference between men and women (model 4). It also revealed higher AL in counties with higher mean years of education (1.042, 1.026 to 1.058). These associations for person-level educational attainment and county-level mean years of education persisted when both variables were included simultaneously (model 5). A two-way interaction term indicated respondents with universitylevel compared with no educational qualification had higher AL when living in counties with higher mean years of education (model 6). A scatterplot of mean AL with respect to person-level educational attainment and county-level mean years of education illustrates this interaction (figure 1). Similar results were observed for these socioeconomic variables, including the two-way interaction, for the other AL variables derived using 75th and 80th percentiles as cut-points (online supplementary tables 5-6).

\section{DISCUSSION}

The purpose of our study was to examine two competing hypotheses ('deprivation amplification' and 'relative deprivation') relating to the socioeconomic and geographical patterning of AL. Using a nationally representative study with objectively measured biomarkers in China, we found evidence clearly supporting neither hypothesis. Instead, it was found that people tend to have higher AL on average and with all other things being equal if they had lower personal educational attainment, which aligns with a wealth of research showing a socioeconomic gradient in health. ${ }^{27}$ But also higher AL was found among people who lived in a county with higher mean years of education, which is the opposite to that found in other countries (eg, Portugal, Switzerland and the UK). ${ }^{16}$ Furthermore, the difference in AL among 
persons with more compared with less personal educational attainment appeared to be amplified when living in counties with higher mean years of education. This expansion was a result of relatively slower growth rete of AL among people with higher educational attainment compared with those with lower educational attainment, as area-level mean years of education grows.

While these results do not fit either hypothesis, they do share a commonality; associations between health status and measures of person-level socioeconomic circumstances are not independent of the contexts in which people live. Higher person-level education may be more likely to be obtained at institutions located within counties where the mean years of education is already higher and aid people in the mobilisation of resources concentrated within those locations for their own gain. Many people may get jobs and remain within those counties or move to other areas with similarly highly educated communities. Others may move to counties with lower mean levels of education and experience a relative increase in their socioeconomic circumstances as a result. These relative gains in status may endow increased levels of esteem, power over local resources and other advantages that translate into lower levels of stress and less AL compared with less educated counterparts nearby, and also with highly educated peers in counties with higher mean years of education.

Meanwhile, within those counties with higher mean years of education, people may in general have better access to healthcare, food and resources, but may also be more likely to experience some of the well-known negatives associated with rapid urbanisation and economic development in China, such as air pollution and increased opportunities to consume unhealthy 'westernised' food. ${ }^{28}$ A high level of personal educational attainment does not inoculate against these negative exposures. Indeed, at the person level, educational attainment likely correlates with income and occupational grade ${ }^{24} 25$ that may increase exposure to some of these negatives (eg, by making 'western' food more affordable) and compounding others (eg, private cars replacing more active means of transportation, such as the bicycle). With the county-level mean years of education likely to be a proxy for many of these contextual exposures, further research to better understand how the dynamic urban form and various intersecting components of the natural and built environment within China's cities may be contributing to higher AL is needed.

Some strengths of this research included the multilevel analysis of a large nationally representative sample with a high response rate $(90.5 \%)$ and the use of nine biomarkers to develop three AL variables with contrasting definitions. Our testing of different AL variables reflected a heterogeneous background literature with many studies using clinical cut-points $\left(\mathrm{eg},{ }^{29}{ }^{30}\right)$ and others using alternative cut-points such as quantiles $\left(\mathrm{eg},{ }^{31}{ }^{32}\right)$. The results across each of the AL variables in our study were consistent regardless of the definition applied.
A further strength was the use of mortality data for purposes of confirming associations found in other studies of AL and risk of death from all causes and NCD-related causes $\left(\mathrm{eg}^{29}{ }^{33}\right)$. There is heterogeneity in the background literature here too, though, with some previous work finding statistically significant associations between AL and all-cause mortality but not with specific causes $\left(\mathrm{eg},{ }^{30}\right)$. Others have reported associations between $\mathrm{AL}$ and all-cause and NCD-related mortality, and also with deaths from infectious diseases $\left(\mathrm{eg},{ }^{32}\right)$, which we did not observe. One reason for these discrepancies may be which biomarkers are available for the construction of AL variables and which are not. Our study, like other work $\left(\mathrm{eg},{ }^{30}\right)$, lacked data on cortisol or other markers of the neuroendocrine system. Putting to one side the challenges of measuring cortisol in large samples such as that analysed in this study, cortisol could be an important omission given the central role that stress is hypothesised to take in the concept of allostasis. Two related limitations are that the biomarker data were cross-sectional and the mortality follow-up was just 5 years. Future research that incorporates markers of the neuroendocrine system, repeated biomarker measurement among the same individuals through time and a longer period of follow-up will all help to build on our current study in useful ways.

In conclusion, this research suggests that while higher educational attainment is associated with lower AL, the magnitude of this association is contingent on the socioeconomic circumstances of the county in which people are resident. This contingency does not reflect those expected from the relative deprivation or deprivation amplification hypotheses. Further work at a neighbourhood scale within China could help to shed new light on these area-based dependencies in AL and socioeconomic circumstances.

\section{Author affiliations}

${ }^{1}$ National Center for Chronic and Non-communicable Disease Control and Prevention, Chinese Center for Disease Control and Prevention, Beijing, China ${ }^{2}$ Population Wellbeing and Environment Research Lab (PowerLab), School of Health and Society, Faculty of Social Sciences, University of Wollongong, Wollongong, New South Wales, Australia

Acknowledgements We thank all involved provincial and local health administrative departments, Centers for Disease Control and Prevention, and over 2000 field interviewers for their hard work during the data collection.

Contributors FM, TA-B and MZ designed and initiated the research. TA-B, FM, XF and $\mathrm{YL}$ carried out the literature search and completed the literature review. $F M$, $Y L, L W$ and $L W$ collected the related data. FM and TA-B completed the data analysis and drafted the article. XF, YL, JD, SL, YJ, WD and MZ made critical revisions, and TA-B and FM wrote the final version of the article. All authors have seen and approved the final version.

Funding This work was supported by the National Key R\&D Program of China (2017YFC1310902), which funded the study design and completion of this paper.

Competing interests None declared.

Patient consent for publication Not required.

Ethics approval Ethnic Review Committee of Chinese Center for Disease Control and Prevention (201010).

Provenance and peer review Not commissioned; externally peer reviewed. 
Data availability statement Data are available on reasonable request and approved by National Center for Chronic and Non-communicable Disease Control and Prevention, China CDC.

Open access This is an open access article distributed in accordance with the Creative Commons Attribution Non Commercial (CC BY-NC 4.0) license, which permits others to distribute, remix, adapt, build upon this work non-commercially, and license their derivative works on different terms, provided the original work is properly cited, appropriate credit is given, any changes made indicated, and the use is non-commercial. See: http://creativecommons.org/licenses/by-nc/4.0/.

ORCID iD

Fan Mao http://orcid.org/0000-0002-0965-4858

\section{REFERENCES}

1 Crews DE, Kawa NC, Cohen JH, et al. Climate change, uncertainty and allostatic load. Ann Hum Biol 2019;46:3-16.

2 Bagby SP, Martin D, Chung ST, et al. From the outside in: biological mechanisms linking social and environmental exposures to chronic disease and to health disparities. Am J Public Health 2019;109:S56-63.

3 Stress MBS. Adaptation, and disease: allostasis and allostatic load. Ann N Y Acad Sci 1998;840:33-44.

4 McEwen BS, Stellar E. Stress and the individual: mechanisms leading to disease. Arch Intern Med 1993;153.

5 Chandola T, Zhang N. Re-employment, job quality, health and allostatic load biomarkers: prospective evidence from the UK Household Longitudinal Study. Int J Epidemiol 2017.

6 McEwen BS, Rasgon NL. The brain and body on stress allostatic load and mechanisms for depression and dementia. In: Strain JJ, Blumenfield M, eds. Depression as a systemic illness. Oxford: Oxford University Press, 2018: 14.

7 Sabbah W, Watt RG, Sheiham A, et al. Effects of allostatic load on the social gradient in ischaemic heart disease and periodontal disease: evidence from the third National Health and Nutrition Examination Survey. J Epidemiol Community Health 2008;62:415-20.

8 Goertzel BN, Pennachin C, de Souza Coelho L, et al. Allostatic load is associated with symptoms in chronic fatigue syndrome patients. Pharmacogenomics 2006;7:485-94.

9 Chen X, Redline S, Shields AE, et al. Associations of allostatic load with sleep apnea, insomnia, short sleep duration, and other sleep disturbances: findings from the National Health and Nutrition Examination Survey 2005 to 2008. Ann Epidemiol 2014;24:612-9.

10 Juster R-P, Marin M-F, Sindi S, et al. Allostatic load associations to acute, 3-year and 6-year prospective depressive symptoms in healthy older adults. Physiol Behav 2011;104:360-4.

11 Karlamangla AS, Singer BH, Seeman TE. Reduction in allostatic load in older adults is associated with lower all-cause mortality risk: MacArthur studies of successful aging. Psychosom Med 2006;68:500-7.

12 Ribeiro A, Amaro J, Lisi C, et al. Neighborhood socioeconomic deprivation and allostatic load: a scoping review. Int $J$ Environ Res Public Health 2018;15:1092.

13 Egorov Al, Griffin SM, Converse RR, et al. Vegetated land cover near residence is associated with reduced allostatic load and improved biomarkers of neuroendocrine, metabolic and immune functions. Environ Res 2017;158:508-21.
14 Buschmann RN, Prochaska JD, Cutchin MP, et al. Stress and health behaviors as potential mediators of the relationship between neighborhood quality and allostatic load. Ann Epidemiol 2018;28:356-61.

15 Johnson SC, Cavallaro FL, Leon DA. A systematic review of allostatic load in relation to socioeconomic position: poor fidelity and major inconsistencies in biomarkers employed. Soc Sci Med 2017;192:66-73.

16 Ribeiro Al, Fraga S, Kelly-Irving M, et al. Neighbourhood socioeconomic deprivation and allostatic load: a multi-cohort study. Sci Rep 2019;9:8790.

17 Macintyre S. Deprivation amplification revisited; or, is it always true that poorer places have poorer access to resources for healthy diets and physical activity? Int J Behav Nutr Phys Act 2007;4.

18 Boyle P, Norman P, Rees P. Changing places. Do changes in the relative deprivation of areas influence limiting long-term illness and mortality among non-migrant people living in non-deprived households? Soc Sci Med 2004;58:2459-71.

19 Wilkinson RG, Inequality I, Cohesion S. And health: Clarifying the Theory-A reply to Muntaner and Lynch. Int J Health Serv 1999;29:525-43.

20 Pettigrew TF. In pursuit of three theories: authoritarianism, relative deprivation, and intergroup contact. Annu Rev Psychol 2016;67:1-21.

21 Marmot MG. Status syndrome. JAMA 2006;295:1304-7.

22 Zhou M, Feng X, Yong J, et al. Lifting the lid on geographic complexity in the relationship between body mass index and education in China. Health Place 2017;46:1-5.

23 National Center for Chronic and Non-communicable Disease Control and Prevention. Report on chronic disease and the risk factors surveillance among Chinese population in 2010: National Center for Chronic and Non-communicable Disease Control and Prevention, China Center for Disease Control and Prevention 2012.

24 Galobardes B, Shaw M, Lawlor DA, et al. Indicators of socioeconomic position (Part 1). J Epidemiol Community Health 2006;60:7-12.

25 Galobardes B, Shaw M, Lawlor DA, et al. Indicators of socioeconomic position (Part 2). J Epidemiol Community Health 2006;60:95-101.

26 Austin PC, Stryhn H, Leckie G, et al. Measures of clustering and heterogeneity in multilevel Poisson regression analyses of rates/ count data. Stat Med 2018;37:572-89.

27 Marmot M. The status syndrome. New York: Henry Holt, 2004: 1. 150-4.

28 Li X, Song J, Lin T, et al. Urbanization and health in China, thinking at the national, local and individual levels. Environmental Health $2016 ; 15$.

29 Levine ME, Crimmins EM. A comparison of methods for assessing mortality risk. Am J Hum Biol 2014;26:768-76.

30 Robertson T, Beveridge G, Bromley C. Allostatic load as a predictor of all-cause and cause-specific mortality in the general population: evidence from the Scottish Health Survey. PLoS One 2017;12:e0183297.

31 Seeman TE, McEwen BS, Rowe JW, et al. Allostatic load as a marke of cumulative biological risk: MacArthur studies of successful aging. Proc Natl Acad Sci U S A 2001;98:4770-5.

32 Hwang A-C, Peng L-N, Wen Y-W, et al. Predicting all-cause and cause-specific mortality by static and dynamic measurements of allostatic load: a 10-year population-based cohort study in Taiwan. J Am Med Dir Assoc 2014;15:490-6.

33 Castagné R, Garès V, Karimi M, et al. Allostatic load and subsequent all-cause mortality: which biological markers drive the relationship? Findings from a UK birth cohort. Eur J Epidemiol 2018;33:441-58. 